\title{
Pattern of Acute Synthetic Cannabinoids Toxicity in Patients Presented to the Poison Control Center of Ain Shams University Hospitals
}

\author{
Asmaa A. Hashem, Suzan M. Mahmoud, Rasha E. Abou Anza and Walaa G. Abdelhamid ${ }^{1}$, \\ ${ }^{1}$ Forensic Medicine and Clinical Toxicology Department, Faculty of Medicine, Ain Shams University, Cairo, Egypt.
}

\begin{abstract}
Background: Toxicity by synthetic cannabinoids (SCs) is increasing steadily with limited data concerning their use. Serious adverse effects after acute exposure to SCs include myocardial ischemia, stroke, seizures, coma, and acute kidney injury.

Aim: Characterization of the epidemiological pattern of acute toxicity by SCs in patients presented to Poison Control Center of Ain Shams University hospitals (PCC-ASUH), Cairo, Egypt; from January 2018 to June 2019, and severity assessment using poisoning severity score (PSS).

Methods: A cross-sectional study included adult patients presented to emergency department of PCC-ASUH from January 2018 to June 2019, with history of acute exposure to SCs.

Results: About 541 patients attended the PCC-ASUH with history of acute SCs toxicity and only 448 patients were enrolled to our study. Males outnumbered females (96.43 versus $3.57 \%$, respectively). Strox predominated $(72.54 \%)$ followed by voodoo $(27.45 \%)$. Recorded PSS was minor in $42.63 \%$ of patients, moderate in $18.97 \%$ and severe in $5.36 \%$. Two patients $(0.45 \%)$ died. Metabolic abnormalities predominated (60\%), followed by gastrointestinal manifestations (46.2\%).

Conclusion: Incidence of SCs toxicity has recently increased. Several variables could worsen PSS in acute SCs poisoning like age, sex, type of SCs, co-ingestion, medical comorbidities, and respiratory acidosis.

Recommendations: Early combination of PSS and arterial blood gas analysis could help in identifying patients at risk for acute SCs toxicity.

Key words Pattern; Poisoning severity score; Synthetic cannabinoids; Toxicity
\end{abstract}

\section{Introduction}

$\mathrm{S}$ ynthetic cannabinoids (SCs) are a heterogeneous group of compounds developed as research tools to explore the endocannabinoid system and as potential therapeutics. The first synthetic cannabinoids, cyclohexylphenols (CP), were synthesized in 1960s by modulating the chemical structure of $\triangle 9$-THC to localize cannabinoid receptors (Johnson and Melvin, 1986) and to study the potential medical benefits of marijuana in immunomodulation, regulation of appetite, addiction, analgesia, and inflammatory regulation (Pertwee, 2006; Vardakou et al., 2010).

In the early 2000s, SCs were synthesized by clandestine laboratories, sprayed on dried plant materials and then marketed as alternatives to traditional cannabis (Crime, 2011). As a result, not only a small community of experimental drug users tried these products, but also a wide proportion of habitual cannabis users as well as a lot of curious people abused them as legal alternatives to cannabis due to their hard detection in standard drugscreening assays of human body fluids (Auwärter et al., 2009; Zanda and Fattore, 2018).

Synthetic cannabinoids (SCs) demonstrate higher binding affinities to $G$ protein-coupled cannabinoid receptors $\mathrm{CB} 1$ and $\mathrm{CB} 2$ when compared to tetrahydrocannabinol (THC) which acts as partial agonist at $\mathrm{CB} 1$ and $\mathrm{CB} 2$ receptors, while $\mathrm{SCs}$ act as full agonists. Additionally, their metabolites have stronger affinities for the previously mentioned receptors resulting in greater potency and longer duration of pharmacologic effects and toxicity (Noble et al., 2019). 
Serious cardiac and neurological adverse effects have been reported after acute exposure to SCs as tachycardia, myocardial ischemia, electrocardiographic abnormalities, anxiety, agitation, stroke, seizures, coma, and psychosis. In addition, acute kidney injury (AKI) in the form of acute tubular necrosis or acute interstitial nephritis has been observed (Thornton et al., 2013; Buser et al., 2014). Unpredictable toxic effects due to unregulated manufacturing processes and variability of ingredients were also declared (Traynor, 2018).

In the United States, Emergency Department visits due to SCs use were tripled in two years, from 11,406 in 2010 to 28,531 in 2011. Their prevalence levels in Europe reached $0.9 \%$ in 2015 compared to $0.2 \%$ in 2012 (Sud et al., 2018). In addition, Centers for Disease Control and Prevention (CDC) found that the number of deaths related to SCs use tripled between 2014 and 2015 where cardiovascular complications were reported as the commonest cause of death (Adamowicz, 2016).

In Europe, SCs are sold under various names as "Spice" by its three subtypes (Silver/ Gold/ Diamond), Yucatan Makes, Yucatan Fire, Sence, Chill X, Smoke, Genie and Shunk. While K2 and K3 are the most popular SCs brands in the USA, Kronic and Bonzai are the commonest brands in Australia. Regarding Egypt, Voodoo and Strox are the commonly used SCs (Solimini et al., 2017).

In contrast to developed countries, there are limited statistical data concerning SCs use in most of the developing Asian and African countries. Up till now, articles that describe acute poisoning with SCs are still insufficient and may focus on one aspect rather than others (Lee et al., 2017).

\section{Aim of the Study:}

We conducted this study to characterize the epidemiological pattern of acute toxicity by $\mathrm{SCs}$ in patients presented to Poison Control Center of Ain Shams University hospitals (PCC-ASUH), Cairo, Egypt; during the period starting from January 2018 to June 2019, and to assess severity of intoxication in studied patients using poisoning severity score (PSS).

\section{Patients and Methods}

Study Design:

This hospital-based cross-sectional study was performed from January 2018 to June 2019 in PCCASUH.

Study population:
All adult patients, of both sex, presented to emergency department (ED) of PCC-ASUH with history of acute exposure to any type of synthetic cannabinoid product were included, even when the patient was considered asymptomatic and directly discharged from the ED. Diagnosis was established by history, physical examination, and routine laboratory evaluation following PCC-ASUH protocols. The study period from January 2018 to December 2018 was considered retrospective using electronic database and medical records while the period from January 2019 to June 2019 was considered prospective.

\section{Study variables:}

Collected data included demographics (age, sex, residence); type of SC agent(s); mode of poisoning; route of exposure; co-ingestion of other agents; pre-hospital management before presentation to PCC-ASUH; medical comorbidities; clinical assessment (neurological, respiratory, cardiovascular, gastrointestinal, and genitourinary); electrocardiogram (ECG) and arterial blood gas findings. We excluded patients below 18 years and above 60 years; and those giving history of having cardiovascular, renal, hepatic or chronic lung diseases.

Criteria of severity and outcome measures:

- Poisoning Severity Score (PSS) of European Association of Poisons Centers and Clinical Toxicologists (EAPCCT) was used to grade severity of poisoning at the time of initial inquiry as indicated by the patient's clinical features (Persson et al., 1998 and Junk et al., 2005). It was intended to be an overall evaluation of the case, taking into account the most severe clinical features. The score has five grades: [None (0): no symptoms or signs related to poisoning; Minor (1): mild, transient, and spontaneously resolving symptoms or signs; Moderate (2): pronounced or prolonged symptoms or signs; Severe (3): severe or life-threatening symptoms or signs; and Fatal (4): death]. Duration of admission in inpatient ward, ICU and patients' outcome were also recorded.

\section{Ethical considerations:}

Administrative approval was obtained from PCCASUH. The Institutional Review Boards of Faculty of Medicine, Ain Shams University approved the protocol (Approval number: FMASU MS 119/2019). An informed consent was obtained from the patients themselves or their legal relatives during the last six months of the study only. Confidentiality of data was maintained by code numbers, and used only for the purpose of epidemiological analysis. 


\section{Statistical analysis:}

Data were tabulated and statistically analyzed using SPSS, version 20 (SPSS Inc., Chicago, IL). Qualitative variables were expressed as frequencies (n) and percentages (\%). Continuous variables were presented as mean (SD) and range. Chi-square test was used to test the association between qualitative variables while ANOVA test was used for comparing quantitative variables. P-value $\leq 0.05$ was considered significant. Spearman Rank-Order Correlation was used to assess the strength of association between two quantitative variables. The correlation coefficient denoted symbolically by " $\mathrm{r}$ " defined the strength and direction of the linear relationship between the two variables.

\section{Results}

Monthly variations in the presentation of studied patients: During the study period, a total of 36,439 patients of acute poisoning attended the ED of PCCASUH, out of which 541 (1.5\%) patients gave history of acute exposure to SCs. Only 448 patients were enrolled to our study and 93 patients were excluded as they were below 18 years or gave history of having chronic liver disease. The majority of studied patients attended the PCC-ASUH in June 2018 followed by May 2018 while the least number of patients were presented in June 2019 as shown in Table 1 and Figure 1.

Demographic characteristics and general health status: All patients were between 18 and 57 years old with mean value $25.8 \pm 7.38$ years. Nearly all patients were males (96.43\%). Demographic characteristics are summarized in Table 2.

Pattern of poisoning: Inhalation was the only route of exposure to SCs $(100 \%)$ mainly via cigarette or shisha smoking. Overdose due to SCs abuse represented the commonest mode of poisoning (85.4\%) followed by accidental poisoning (14.6\%). Strox predominated (72.54\%) followed by voodoo (27.45\%) as presented in Table 3.

Co-ingestion, pre-hospital management and admission status: About $83.48 \%$ of patients were poisoned with single SC agent and only $16.52 \%$ ingested other drugs or agents in addition to SCs. Tramadol topped the list accounting for $44.59 \%$ of co-ingested substances followed by antipsychotics, mainly clozapine (14.86\%). Thirty six (8.03\%) patients were hospitalized for further treatment, of which 27 (75\%) patients required ICU admission as presented in Table 4.

Clinical manifestations: Metabolic abnormalities due to acid-base disturbances predominated 269 (60\%), followed by gastrointestinal manifestations 207 (46.2\%). Vomiting and epigastric pain were the only GIT symptoms in the studied patients where vomiting occurred in 164 (36.61\%) patients followed by epigastric pain in $108(24.11 \%)$ patients. Moderate neurological manifestations were observed in $17.41 \%$ of cases in the form of confusion and hallucinations with only $5.81 \%$ of cases experienced severe manifestations as deep coma, extreme agitation or generalized convulsions. Respiratory symptoms affected only $16.3 \%$ of patients. Minor affection (mainly breathlessness) was found in $12.95 \%$ of the total number of studied patients while respiratory insufficiency denoting severe affection developed in $3.35 \%$ of patients. About $2.46 \%$ of patients showed minor cardiovascular symptoms as isolated extrasystole while $3.13 \%$ of patients had moderate cardiovascular symptoms in the form of sinus bradycardia (HR 40-50 beats/min) and only one patient developed severe symptoms manifested as severe sinus bradycardia (HR $<40$ beats/min). (Table 5). All studied patients did not show any genitourinary manifestations.

Poisoning severity score and outcome: Poisoning severity score was minor in 191 (42.63\%) patients, moderate in 85 (18.97\%) patients, and severe in 24 (5.36\%) patients; while 146 patients (32.59\%) were asymptomatic. Two patients $(0.45 \%)$ died showing PSS (4) where the causative agent was strox.

Factors affecting PSS: Increasing age, male sex, presence of medical comorbidities and overdose due to SCs abuse were associated with PSS increase. Patients intoxicated by strox showed higher PSS compared to voodoo poisoned patients. Residence and pre-hospital management had no effect on PSS as displayed in Table 6. Respiratory acidosis was the main acid-base disturbance that directly affected PSS. In addition, length of hospital stay did not affect PSS as shown in Table 7.

Causes of ICU admission: Coma was the commonest cause of ICU admission ( $\mathrm{n}=22$ ). Only three patients developed isolated cardiovascular complications, mainly sinus bradycardia. (Table 8)

Both delay time and length of stay showed negative correlation with PSS. On the other hand, a positive correlation was observed between length of stay in ICU and PSS. However, these correlations seemed to be statistically non-significant. (Table 9) 
Table (1): Monthly variations in the presentation of acutely poisoned patients with synthetic cannabinoids under the study ( $\mathbf{N}=\mathbf{5 4 1})$

\begin{tabular}{|c|c|c|c|}
\hline Year & Month & $\mathbf{N}$ & Percentage \% \\
\hline \multirow{12}{*}{2018} & January & 45 & 8.32 \\
\hline & February & 29 & 5.36 \\
\hline & March & 25 & 4.62 \\
\hline & April & 52 & 9.61 \\
\hline & May & 67 & 12.38 \\
\hline & June & 68 & 12.57 \\
\hline & July & 56 & 10.35 \\
\hline & August & 37 & 6.84 \\
\hline & September & 36 & 6.65 \\
\hline & October & 19 & 3.51 \\
\hline & November & 20 & 3.70 \\
\hline & December & 18 & 3.33 \\
\hline \multirow{7}{*}{2019} & January & 16 & 2.96 \\
\hline & February & 12 & 2.22 \\
\hline & March & 14 & 2.59 \\
\hline & April & 12 & 2.22 \\
\hline & May & 10 & 1.85 \\
\hline & June & 5 & 0.92 \\
\hline & Total & 541 & 100.00 \\
\hline
\end{tabular}

Table (2): Demographic characteristics and medical comorbidities among synthetic cannabinoids intoxicated patients under the study $(\mathrm{N}=448)$

\begin{tabular}{|l|c|c|}
\hline & $\mathbf{N}$ & $\mathbf{\%}$ \\
\hline Mean age (SD) (years) & 448 & $25.8(7.38)$ \\
\hline Sex & & 96.43 \\
\hline Male & 432 & 3.57 \\
\hline Female & 16 & 82.59 \\
\hline Residence & & 17.41 \\
\hline Urban & 370 & \\
\hline Rural & 78 & 99.55 \\
\hline Presence of medical comorbidities & & 0.45 \\
\hline Negative & 446 & \\
\hline Positive & $2^{*}$ & \\
\hline
\end{tabular}

(*): Diabetes mellitus / Familial Mediterranean Fever

Table (3): Types of synthetic cannabinoid agents in relation to mode of intoxication in synthetic cannabinoids intoxicated patients under the study $(\mathrm{N}=448)$

\begin{tabular}{|c|c|c|c|c|c|c|}
\hline \multirow{3}{*}{ SC agent } & \multicolumn{4}{|c|}{ Mode of intoxication } \\
\cline { 2 - 7 } & \multicolumn{2}{|c|}{ Overdose due to SCs abuse } & \multicolumn{2}{c|}{ Accidental } & \multicolumn{2}{c|}{ Total } \\
\cline { 2 - 7 } & $\mathbf{N}$ & $\mathbf{0}$ & $\mathbf{N}$ & $\mathbf{\%}$ & $\mathbf{N}$ & $\mathbf{\%}$ \\
\hline Strox & 280 & 72.72 & 45 & 71.43 & 325 & 72.54 \\
\hline Voodoo & 105 & 27.27 & 18 & 28.57 & 123 & 27.45 \\
\hline Total & 385 & 85.4 & 63 & 14.6 & 448 & 100.00 \\
\hline
\end{tabular}

\%: Percentage. N: Number of patients SCs: Synthetic cannabinoids 
Table (4): Delay time, co-ingestion, pre-hospital management, admission rate and length of hospital stay in the studied patients $(\mathrm{N}=\mathbf{4 4 8})$

\begin{tabular}{|c|c|c|}
\hline & $\mathbf{N}$ & $\%$ \\
\hline Delay time (Hours) & & $7.723 \quad \pm 7.398$ \\
\hline \multicolumn{3}{|l|}{ Co-ingestion } \\
\hline Negative & 374 & 83.48 \\
\hline Positive & 74 & 16.52 \\
\hline \multicolumn{3}{|l|}{ Types of co-ingested agents } \\
\hline Tramadol & 33 & 44.59 \\
\hline Antipsychotics (clozapine) & 11 & 14.86 \\
\hline Oral hypoglycemic & 9 & 12.16 \\
\hline Pregabalin & 8 & 10.81 \\
\hline Carbamazepine & 8 & 10.81 \\
\hline Organophosphates & 5 & 6.75 \\
\hline \multicolumn{3}{|l|}{ Pre-hospital Management } \\
\hline Negative & 414 & 92.41 \\
\hline Proper & 34 & 7.59 \\
\hline Patients admitted in inpatient ward & 9 & 2.01 \\
\hline Length of stay in inpatient (Days) & & $1.61 \pm 0.97$ \\
\hline Patients admitted in ICU & 27 & 6.02 \\
\hline Length of stay in ICU (Days) & & $1.59 \pm 0.69$ \\
\hline Total patients admitted to hospital & 36 & 8.03 \\
\hline Total length of stay (Days) & & $2.0 \pm 1.41$ \\
\hline
\end{tabular}

Table (5): The frequency of poisoning severity score according to the body system involved $(\mathrm{N}=448)$

\begin{tabular}{|l|c|r|r|r|r|r|r|r|}
\hline \multirow{2}{*}{} & \multicolumn{2}{|c|}{ None } & \multicolumn{2}{c|}{ Minor } & \multicolumn{2}{c|}{ Moderate } & \multicolumn{2}{c|}{ Severe } \\
\cline { 2 - 9 } & $\mathrm{N}$ & \multicolumn{1}{c|}{$\%$} & \multicolumn{1}{c|}{$\mathrm{N}$} & \multicolumn{1}{c|}{$\%$} & $\mathrm{~N}$ & \multicolumn{1}{c|}{$\%$} & \multicolumn{1}{c|}{ \% } \\
\hline Metabolic & 179 & $39.96 \%$ & 182 & $40.63 \%$ & 67 & $14.96 \%$ & 20 & $4.46 \%$ \\
\hline Gastrointestinal & 241 & $53.79 \%$ & 148 & $33.04 \%$ & 59 & $13.17 \%$ & 0 & $0.0 \%$ \\
\hline Neurological & 344 & $76.79 \%$ & 0 & $0.0 \%$ & 78 & $17.41 \%$ & 26 & $5.8 \%$ \\
\hline Respiratory & 375 & $83.71 \%$ & 58 & $12.95 \%$ & 0 & $0.0 \%$ & 15 & $3.35 \%$ \\
\hline Cardiovascular & 422 & $94.2 \%$ & 11 & $2.46 \%$ & 14 & $3.13 \%$ & 1 & $0.22 \%$ \\
\hline
\end{tabular}


Table (6): Poisoning severity score in relation to demographics, type of synthetic cannabinoids, and pattern of intoxication $(\mathbf{N}=\mathbf{4 4 8})$

\begin{tabular}{|c|c|c|c|c|c|c|}
\hline & \multicolumn{5}{|c|}{ PSS } & \multirow{3}{*}{$P$ value } \\
\hline & $\begin{array}{c}\text { Asymptomatic } \\
\text { (0) }\end{array}$ & $\begin{array}{l}\text { Minor } \\
\text { (1) }\end{array}$ & $\begin{array}{l}\text { Moderate } \\
\text { (2) }\end{array}$ & Severe (3) & Fatal (4) & \\
\hline & N (\%) & N (\%) & N (\%) & N (\%) & N (\%) & \\
\hline Age (Years) ${ }^{!}$ & $25.38+7.4$ & $26.0 \pm 7.4$ & $25.4 \pm 6.1$ & $28.3+8.8$ & $42.0+14.1$ & $0.009 *$ \\
\hline \multicolumn{7}{|l|}{ Sex } \\
\hline Male & 144 (33.33) & 181(41.9) & $84(19.4)$ & $22(5.1)$ & $1(0.23)$ & $0.001 *$ \\
\hline Female & $2(12.5)$ & $10(62.5)$ & $1(6.25)$ & $2(12.5)$ & $1(6.25)$ & \\
\hline \multicolumn{7}{|l|}{ Residence } \\
\hline Urban & 116(31.3) & $160(43.2)$ & $70(19)$ & $22(6)$ & $2(0.5)$ & 0.56 \\
\hline Rural & $30(38.5)$ & $31(39.7)$ & $15(19.2)$ & $2(2.6)$ & $0(0)$ & \\
\hline \multicolumn{7}{|l|}{$\begin{array}{l}\text { Presence of medical } \\
\text { comorbidities }\end{array}$} \\
\hline Negative & $146(32.7)$ & 191(42.8) & 84(18.8) & $24(5.4)$ & $1(0.2)$ & $<0.001^{*}$ \\
\hline Positive & $0(0)$ & $0(0)$ & $1(50)$ & $0(0)$ & $1(50)$ & \\
\hline \multicolumn{6}{|l|}{ Type of SC agent } & \multirow{3}{*}{$<0.001^{*}$} \\
\hline Strox & $115(35.4)$ & 128(39.4) & 61(18.8) & $19(5.8)$ & $2(0.6)$ & \\
\hline Voodoo & $31(25.2)$ & $63(51.2)$ & $24(19.5)$ & $5(4.06)$ & $0(0)$ & \\
\hline \multicolumn{6}{|l|}{ Co-ingestion } & \multirow{3}{*}{$<0.001^{*}$} \\
\hline Negative & 136(36.36) & $163(43.6)$ & $66(17.6)$ & $9(2.4)$ & $0(0)$ & \\
\hline Positive & $10(13.5)$ & $28(37.8)$ & 19(25.7) & $15(20.3)$ & $2(2.7)$ & \\
\hline \multicolumn{7}{|l|}{ Pre-hospital management } \\
\hline Negative & 141(34) & 173(41.8) & $76(18.35)$ & $22(5.3)$ & $2(0.5)$ & 0.215 \\
\hline Proper & $5(14.7)$ & 18(52.9) & $9(26.5)$ & $2(5.9)$ & $0(0)$ & \\
\hline \multicolumn{7}{|l|}{ Mode of poisoning } \\
\hline Overdose due to abuse & 133(34.5) & 159(41.3) & $68(17.7)$ & $23(5.97)$ & $2(0.5)$ & $0.038 *$ \\
\hline Accidental & $13(20.6)$ & $32(50.8)$ & $17(26.98)$ & $1(1.6)$ & $0(0)$ & \\
\hline
\end{tabular}

Table (7): Poisoning severity score in relation to arterial blood gas analysis and length of stay $(\mathrm{N}=448)$

\begin{tabular}{|c|c|c|c|c|c|c|}
\hline & \multicolumn{5}{|c|}{ PSS } & \multirow{3}{*}{$\begin{array}{c}\mathbf{P} \\
\text { value }\end{array}$} \\
\hline & Asymptomatic (0) & Minor (1) & Moderate (2) & Severe (3) & Fatal (4) & \\
\hline & N (\%) & N (\%) & N (\%) & N (\%) & N (\%) & \\
\hline \multicolumn{7}{|l|}{ ABG findings } \\
\hline Normal & $120(67)$ & $49(27.4)$ & $10(5.6)$ & $0(0)$ & $0(0)$ & \\
\hline Respiratory acidosis & $18(9.9)$ & 99(54.4) & $41(22.5)$ & $22(12.1)$ & $2(1.1)$ & $<0.001^{*}$ \\
\hline Respiratory alkalosis & $8(9.2)$ & $43(49.4)$ & $34(39.1)$ & $2(2.3)$ & $0(0)$ & \\
\hline $\begin{array}{l}\text { Length of stay in inpatient } \\
\text { (Days)! }\end{array}$ & -- & $1.75 \pm .5$ & $1.71 \pm 1.1$ & $1.4 \pm 1.1$ & -- & 0.84 \\
\hline $\begin{array}{l}\text { Length of stay in ICU } \\
\text { (Days)! }\end{array}$ & -- & -- & $1.56 \pm 0.7$ & $1.56 \pm 0.6$ & $2.0 \pm 1.4$ & 0.7 \\
\hline $\begin{array}{l}\text { Total length of stay } \\
\text { (Days)! }\end{array}$ & -- & $1.75 \pm .5$ & $1.86 \pm 1.6$ & $2.2 \pm 1.4$ & $2.0 \pm 1.4$ & 0.9 \\
\hline
\end{tabular}

Chi square test was used, (!) ANOVA test was used, PSS: Poisoning severity score, $(*)$ : statistically significant difference 
Table (8): Causes of ICU admission in acutely intoxicated patients by synthetic cannabinoids $(\mathrm{N}=27)$

\begin{tabular}{|c|c|c|}
\hline \multicolumn{3}{|c|}{ Causes of ICU admission } \\
\hline Coma with agitation & $\mathbf{N}$ & \% \\
\hline Coma & 13 & 48.15 \\
\hline Coma + CVS & 6 & 11.22 \\
\hline CVS & 3 & 11.11 \\
\hline Agitation & 3 & 7.40 \\
\hline Total & 2 & 100.00 \\
\hline
\end{tabular}

N: Number of patients, ICU: Intensive care unit, CVS: Cardiovascular complications

Table (9): Spearman correlation analysis between delay time, length of stay in inpatient/ICU and poisoning severity score in patients under the study $(\mathrm{N}=448)$

\begin{tabular}{|c|c|c|}
\hline Spearman's rho Correlations & \multicolumn{2}{|c|}{ PSS } \\
\hline & R & P-value \\
\hline Delay time (Hours) & -0.067 & 0.160 \\
\hline Length of stay in the inpatient ward (Days) & -0.372 & 0.129 \\
\hline Length of stay in ICU (Days) & 0.078 & 0.700 \\
\hline Total length of stay (Days) & 0.166 & 0.334 \\
\hline
\end{tabular}

PSS: Poisoning severity score, $P>0.05$ : Non significant difference, $r$ : Correlation coefficient

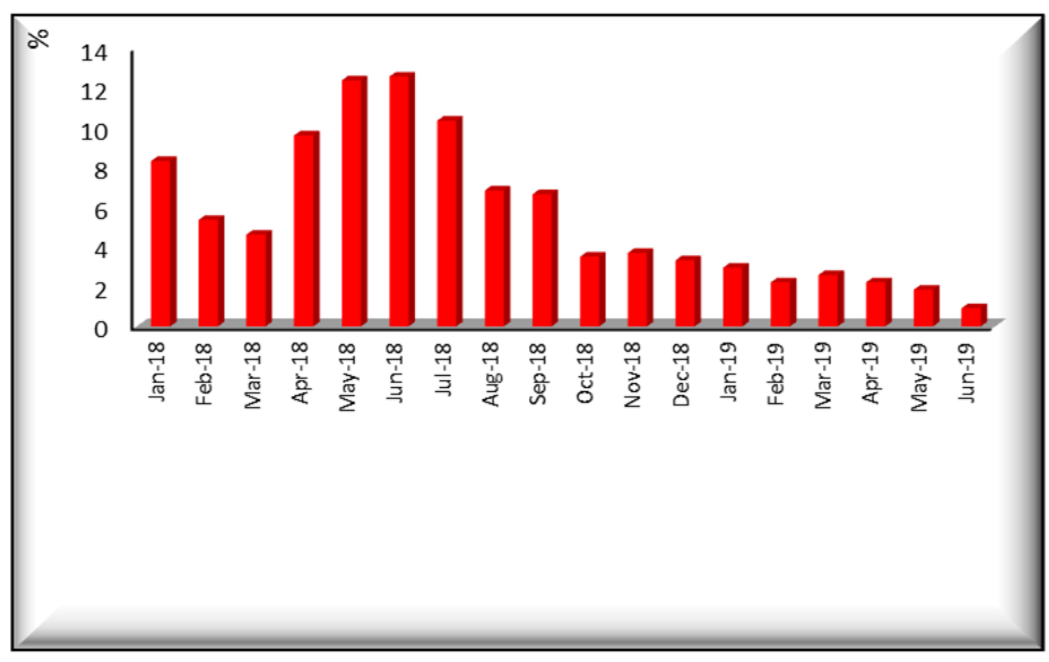

Figure (1): Monthly variations in the presentation of acutely synthetic cannabinoids poisoned patients in our study.

\section{Discussion}

The present study characterizes pattern of acute intoxication by SCs in patients presented to PCC-ASUH. The mean age value for all patients was $25.8 \pm 7.38$ years. Nearly similar results were obtained in an Australian study done by Barratt et al. (2013). The possible reasons for increased incidence of drug abuse in this age may be attributed to psychological family problems, studying, marriage, life costs and unemployment which make them stressed with probable involvement in drug abuse (Jesslin et al., 2010). On the other hand, different mean age values were reported in USA and Turkey by Bonar et al. (2014) and Besli et al.
(2015) who recorded mean age of $34.8 \pm 10.7$ and $15.4 \pm$ 1.7 years respectively.

In the current study, male intoxicated patients were represented at a higher rate than females $(96.4 \%$ and $3.6 \%$ respectively), and showed higher PSS compared to females. This agreed with Winstock \& Barratt (2013) and Jones (2020) where males were more affected than females in United Kingdom. Males generally show aggressive (externalizing) behaviors during personal problems compared to females who often show auto-aggressive (internalizing) symptomatology. So self-poisoning is the main manner of intoxication in females; whereas drug abuse and addiction are more common in males (Foto-Özdemir et al., 2016). Moreover, 
women with encountered substance abuse problems mostly show unique barriers to seeking medical help owing to greater stigma, limited access to insurance coverage for addiction treatment and less family support for seeking medical advice (Alvanzo et al., 2014). The reverse was observed by Maxwell et al. (2017) who found that females were highly represented in their American study.

In the present study, overdose due SCs abuse represented the main mode of intoxication $(85.4 \%)$. In addition, SCs abusers showed higher PSS compared to accidentally intoxicated patients. This was in accordance with Maxwell (2018) who reported that overdose due to SCs abuse was the main mode of intoxication in patients presented to Texas Poison Center Network in 2014 and 2015. On the contrary, Darke et al. (2020) declared that accidental SCs toxicity had been strongly associated with severity and implicated in some fatal cases in Australia.

Strox was the commonest synthetic cannabinoid compound mostly involved in acute intoxication $(72.54 \%)$ and was associated with significantly higher PSS when compared to voodoo in the studied patients. To date, some reports considered voodoo and strox as pure SCs, while others reported presence of hallucinogens such as atropine, hyoscine and hyoscyamine. As a result, little is actually known regarding their exact composition, toxicity profile and their effects on severity scores (Hussien et al., 2020). Waugh et al. (2016) noticed significant difference in PSS regarding intoxication by different SCs where "Pandora's Box" was associated with significantly higher PSS compared to "Clockwork Orange". No significant difference in PSS was observed when "Pandora's Box" was compared with "Black Mamba" in the same study.

In the current study, inhalation was the only route of intoxication by different types of SCs. Similarly, Bonar et al. (2014) and Law et al. (2015) reported that inhalation via smoking was the commonest route of SCs administration, representing $91 \%$ and $80.3 \%$ of all routes respectively, using cigarettes, vaporizers, water pipes or bongs while SCs ingestion occurred in only 3\% and $19.5 \%$ respectively. Synthetic cannabinoid users mostly prefer inhalational products than oral ones as oral consumption has delayed onset of action. In addition, oral forms are easily ingested without any pleasure during preparation (Huestis and Smith, 2018).

It was clear that co-ingestion of other drugs or agents significantly affect the PSS of the studied patients. This result was extremely logic as the co-ingested drugs were mostly tramadol accounting for $44.59 \%$ of coingested substances followed by antipsychotics, mainly clozapine $(14.86 \%)$, which are well-known to be unsafe medications and greatly affect the clinical course of poisoning owing to tramadol-induced respiratory depression and antipsychotics-induced cardiotoxicity (Lagard et al., 2018; Li et al., 2019). In studies done by Bonar et al. (2014) and Law et al. (2015), alcohol topped the list of co-ingested agents (96\%), followed by cannabis and prescriptive opioids in USA.

Despite the small number of our studied patients who reported history of having medical illnesses, they showed the highest PSS. This could be explained by the impacts of underlying medical diseases which could probably worsen the clinical course of acute intoxication, influence the route of metabolism or elimination of various drugs and thus predispose to increased drug toxicity (Rehm et al., 2017).

About 207 (46.2\%) patients complained of gastrointestinal manifestations in our study, where vomiting and epigastric pain were the only symptoms. Similar results were reported by Trecki et al. (2015). Gastrointestinal manifestations owed to SCs could be explained by their inhibitory effect on electricallyinduced contractions of small intestine causing delayed solid-phase gastric emptying. Thus, repetitive vomiting and abdominal pain are the most prominent gastrointestinal symptoms among SCs abusers (Robinson et al., 2013).

In the current study, moderate neurological manifestations were observed in $17.41 \%$ of cases in the form of confusion and hallucinations with only $5.81 \%$ of cases experienced severe manifestations as deep coma, extreme agitation or generalized convulsions. These results agreed with Riederer et al. (2016) who found that agitation, hallucinations and perceptual changes were the main neurological findings among their studied SCs abusers followed by CNS depression. Inhibition of gamma-aminobutyric acid neurotransmission in the brain may play a role in the development of anxiety, agitation and convulsions in most SCs abusers. In addition, absence of phytocannabinoids (e.g. cannabinol and cannabidiol) in synthetic cannabinoid preparations with subsequent loss of their anticonvulsant properties increases the risk for developing agitation and convulsions (Harris and Brown, 2013).

To the best of our knowledge, few toxicological case reports were found to show a link between SCs and respiratory dysfunction (Herbst and Musgrave, 2020). The effect of SCs on chemoreceptors and baroreceptors can increase bronchial airway resistance. In addition, CB1 receptor stimulation by SCs induces respiratory depression, and lastly numerous chemical gases released after SCs inhalation may cause damage to the bronchiolar epithelium and disrupt the protective surfactant layer in the alveoli, resulting in interference with effective gas exchange with subsequent hypoxia and acidosis (Alon and Saint-Fleur, 2017).

Cardiovascular manifestations, either extrasystole or bradycardia, occurred in only $5.8 \%$ of studied patients. Several theories suggested that SCs were found to elicit dose-dependent bradycardia mediated by CB1 receptors (Ozturk et al., 2019). Cardiac abnormalities could be also justified by the prolonged or potent effects of SCs on cardiac conduction system and myocytes, leading to decreased stroke volume and dysrhythmias in 
comparison with traditional cannabis (Von Der Haar et al., 2016). On the contrary, tachycardia and hypertension have been mostly observed among SCs abusers in similar studies (Trecki et al., 2015; Monte et al., 2017).

Respiratory acidosis was the most prominent acidbase disturbance affecting $40.63 \%$ of the total number of studied patients. These results were in agreement with Besli et al. (2015) who reported that respiratory acidosis predominated in $40 \%$ of their Turkish studied patients. Respiratory acidosis induced by SCs could be attributed to decreased sensitivity of central and peripheral chemoreceptors to carbon dioxide (Ridgway and Pountney, 2007). Additionally, SCs may cause pulmonary edema due to diffusion impairment and ventilationperfusion mismatch leading to hypoxia and hypercapnea with subsequent respiratory acidosis (Wilkins et al., 2013). It was clear that respiratory acidosis was the main acid-base disturbance that directly affected the PSS in the present study. This was explained by Romito et al. (2018) who stated that respiratory acidosis causes cerebral vasodilation with increased cerebral blood flow and raised intracranial tension; finally central depression may occur at very high levels of PCO2, manifested by dyspnea, disorientation, acute confusion or headache leading to high PSS. On the other hand, Yasar-Durmus et al. (2015) did not record any acid-base disturbance among their Turkish SCs abusers.

Nearly $8.02 \%$ of our patients required hospital admission for further management. Wide variations regarding hospital stay were reported where Barratt et al. (2013) found that only $1.8 \%$ of their studied patients need hospital admission following SCs exposure while Riederer et al. (2016) reported hospital admission in $58.6 \%$ of SCs intoxicated patients.

It was observed that PSS (1) was recorded in the majority of patients $(42.63 \%)$ followed by PSS (0) in $32.59 \%$ of cases while death occurred in two $(0.45 \%)$ patients with PSS (4). Nearly similar results were reported by Maxwell (2018) where PSS (0) was recorded in $30 \%$ of patients and only $3 \%$ showed PSS (3). On the other hand, Hermanns-Clausen et al. (2013) recorded PSS (2) in the majority of their patients (58\%) followed by PSS (1) in $37 \%$ of patients.

In the current study, the mortality rate was $0.45 \%$ and strox was responsible for death in the two deceased patients. The first case was a 32-year old male, presented with history of strox inhalation 24 hours before presentation and coma grade IV (by Reed's classification of level of consciousness). Arterial blood gas analysis revealed severe respiratory acidosis and his ECG showed sinus bradycardia. The patient was admitted in the ICU and mechanically ventilated for two days then he developed cardiac arrest.

The second case was a 52-year old female, who developed agitation and coma grade IV two hours after strox inhalation. Arterial blood gas analysis revealed severe respiratory acidosis and her ECG was normal. The patient was admitted in the ICU and mechanically ventilated for three days then she developed repetitive seizures and cardiac arrest. Riederer et al. (2016) recorded mortality rate of $1.2 \%$ in a similar study where K2/Spice was the only causative agent. Their study documented cardiac arrest, respiratory depression and acute kidney injury as the major causes of death due to acute SCs intoxication.

\section{Conclusion}

Incidence of SCs toxicity has recently increased in Egypt and strox was the commonest brand of SCs abused by patients. To date, little is known about the pattern of acute poisoning by SCs. However, several variables could worsen the PSS in acute SCs poisoning like age, sex, type of SCs, overdose due to SCs abuse, presence of co-ingestion, medical comorbidities, and presence of respiratory acidosis while other variables seem to have no effect on PSS as residence, delay time and prehospital management.

\section{Recommendations}

Early combination of PSS and arterial blood gas analysis could help in identifying patients at risk for acute SCs toxicity and even those who might progress to severe fatal poisoning. After recovery, patients should be referred for psychiatric consultation, as many have history of poly-substance abuse. Public education by raising awareness among youth about the potential harms of SCs could help in reducing addiction and its related poisoning episodes in this age group. Further multicenter-based studies are needed to provide a more comprehensive picture of acute SCs poisoning, including larger number of patients for more extended time period than 18 months. Further studies are needed to portray and compare the pattern of acute SCs poisoning in different age groups.

\section{Strengths and limitations:}

Although the sample size of the present study was enough to reach conclusion, an important limitation is that it included patients who were presented to PCCASUH, which is a single Egyptian toxicological center and might not globally represent the pattern of acute SCs intoxication in the whole country. We could expect a greater number of SCs intoxicated patients who were managed at other hospitals or health care centers. Due to exclusion of patients less than 18 years and more than 60 years from the study, the burden of pediatric intoxication and the effect of age in elderly could not be assessed.

\section{References}

Adamowicz P (2016): Fatal intoxication with synthetic cannabinoid MDMB-CHMICA. Forensic Science International, 261: e5-e10.

Alon M and Saint-Fleur M (2017): Synthetic cannabinoid induced acute respiratory depression: Case series and literature review. Respiratory medicine case reports, 22:137-141. 
Alvanzo A, Storr C, Mojtabai R, et al., (2014): Gender and race/ethnicity differences for initiation of alcohol-related service use among persons with alcohol dependence. Drug and alcohol dependence, 140: 48-55.

Auwärter V, Dresen S, Weinmann W, et al., (2009): 'Spice'and other herbal blends: harmless incense or cannabinoid designer drugs? Journal of Mass Spectrometry, 44(5): 832-837.

Barratt M, Caki V and Lenton S (2013): Patterns of synthetic cannabinoid use in Australia. Drug and alcohol review, 32(2): 141-146.

Besli G, Ikiz M, Yildirim S, et al., (2015): Synthetic cannabinoid abuse in adolescents: a case series. The Journal of Emergency Medicine, 49(5): 644650.

Bonar E, Ashrafioun L and Ilgen M (2014): Synthetic cannabinoid use among patients in residential substance use disorder treatment: prevalence, motives, and correlates. Drug and Alcohol Dependence, 143: 268-271.

Buser G, Gerona R, Horowitz B, et al., (2014): Acute kidney injury associated with smoking synthetic cannabinoid. Clinical toxicology, 52(7): 664-673.

Crime, U. N. O. on D (2011): 2011 Global Study on Homicide: Trends, Contexts, Data (Global Study on Homicide: trends, Contexts, Data, 2011).United Nations Office on Drugs and Crime.

Darke S, Duflou J, Farrell M, et al., (2020): Characteristics and circumstances of synthetic cannabinoid-related death. Clinical toxicology, 58(5): 368-374.

Foto-Özdemir D, Akdemir D and Çuhadaroğlu-Çetin F (2016): Gender differences in defense mechanisms, ways of coping with stress and sense of identity in adolescent suicide attempts. Turkish Journal of Pediatrics, 58(3).

Harris C and Brown A (2013): Synthetic cannabinoid intoxication: a case series and review. The Journal of Emergency Medicine, 44(2): 360-366.

Herbst J and Musgrave G (2020): Respiratory depression following an accidental overdose of a CBDlabeled product: A pediatric case report. Journal of the American Pharmacists Association, 60(1): 248-252.

Hermanns $\square$ Clausen M, Kneisel S, Szabo B, et al., (2013): Acute toxicity due to the confirmed consumption of synthetic cannabinoids: clinical and laboratory findings. Addiction, 108(3): 534544.

Huestis M and Smith M (2018): Cannabinoid markers in biological fluids and tissues: revealing intake. Trends in molecular medicine, 24(2): 156-172.

Hussien R, Ahmed S, Awad H, et al., (2020): Identification of 'Voodoo': an emerging substance of abuse in Egypt. International Journal of Environmental Analytical Chemistry, 1-13.
Jesslin J, Adepu R and Churi S (2010): Assessment of prevalence and mortality incidences due to poisoning in a South Indian tertiary care teaching hospital. Indian journal of pharmaceutical sciences, 72(5): 587.

Johnson M and Melvin L (1986): The discovery of nonclassical cannabinoid analgetics. In: Cannabinoids as Therapeutic Agents, Raphael M (ed.), CRC Press, Boca Raton, Florida, ch. (7), pp: 121- 145 .

Jones S (2020): Notes from the Field: Syndromic Surveillance used to monitor emergency department visits during a synthetic cannabinoid overdose outbreak - connecticut, August 2018. MMWR morbidity and mortality weekly report, 69.

Junk SH, Park DY, Park JS, et al., (2005): Significance of the poisoning severity score as a prognostic factor in poisoning. J Korean Soc Emerg Med, 16:660666.

Lagard C, Malissin I, Indja W, et al., (2018): Is naloxone the best antidote to reverse tramadol-induced neuro-respiratory toxicity in overdose? An experimental investigation in the rat. Clinical Toxicology, 56(8): 737-743.

Law R, Schier J, Martin C, et al., (2015): Increase in reported adverse health effects related to synthetic cannabinoid use-United States, January-May 2015. MMWR, morbidity and mortality weekly report, 64(22): 618.

Lee J, Yang S, Kang Y, et al., (2017): Prevalence of new psychoactive substances in Northeast Asia from 2007 to 2015. Forensic Science International, 272: $1-9$.

Li L, Dong X, Tu C, et al., (2019): Opposite effects of cannabinoid $\mathrm{CB} 1$ and $\mathrm{CB} 2$ receptors on antipsychotic clozapine $\square$ induced cardiotoxicity. British journal of pharmacology, 176(7): 890-905.

Maxwell J (2018): The changing face of synthetic cannabinoids in Texas. Journal of Psychoactive Drugs, 50(4): 281-286.

Maxwell S, Delaney H and Kelley K (2017): Designing experiments and analyzing data: A model comparison perspective. In: Theory Construction and Model-Building Skills, James J, Jacob J (eds.), 2nd ed., the Guilford press, New York, ch. (1), pp22-52.

Monte A, Calello D, Gerona R, et al., (2017): Characteristics and treatment of patients with clinical illness due to synthetic cannabinoid inhalation reported by medical toxicologists: a ToxIC database study. Journal of Medical Toxicology, 13(2): 146-152.

Noble C, Cannaert A, Linnet K, et al., (2019): Application of an activity $\square$ based receptor bioassay to investigate the in vitro activity of selected indole $\square$ and indazole $\square 3 \square$ carboxamide $\square$ based synthetic cannabinoids at $\mathrm{CB} 1$ and $\mathrm{CB} 2$ 
receptors. Drug Testing and Analysis, 11(3): 501511.

Ozturk H, Yetkin E and Ozturk S (2019): Synthetic cannabinoids and cardiac arrhythmia risk: Review of the literature. Cardiovascular Toxicology, 19(3): 191-197.

Persson H, Sjoberg G, Haines J, et al., (1998): Poisoning severity score. Grading of acute poisoning. J Toxicol Clin Toxicol, 36(3):205-213.

Pertwee R (2006): The pharmacology of cannabinoid receptors and their ligands: an overview. International journal of obesity, 30(1): 13-18.

Rehm J, Gmel S, and Gmel G (2017): The relationship between different dimensions of alcohol use and the burden of disease-an update. Addiction, 112(6): 968-1001.

Ridgway Z and Pountney A (2007): Acute respiratory distress syndrome induced by oral methadone managed with non-invasive ventilation. Emergency Medicine Journal, 24(9): 681-681.

Riederer A, Campleman S, Carlson R, et al., (2016): Acute poisonings from synthetic cannabinoids50 US toxicology investigators consortium registry sites, 2010-2015. MMWR, morbidity and mortality weekly report, 65(27): 692.

Robinson T, Cheng F, Domingo C, et al., (2013): Spicing up the differential for cyclical vomiting. American Journal of Gastroenterology, 108(8): 1371.

Romito J, Bhoja R and McDonagh D (2018): Central and Peripheral Nervous Systems. Basic Sciences in Anesthesia, 271-297.

Solimini R, Busardò F, Rotolo M, et al., (2017): Hepatotoxicity associated to synthetic cannabinoids use. Eur Rev Med Pharmacol Sci, 21(1 Suppl): 1-6.

Sud P, Gordon M, Tortora L, et al., (2018): Retrospective chart review of synthetic cannabinoid intoxication with toxicologic analysis. Western Journal of Emergency Medicine, 19(3): 567.

Thornton S, Wood C, Friesen M, et al., (2013): Synthetic cannabinoid use associated with acute kidney injury. Clinical Toxicology, 51(3): 189-190.
Traynor K (2018): Illinois hospitals cope with outbreak of bleeding linked to tainted cannabinoids. Am J Health Syst Pharm, 75:728-732.

Trecki J, Gerona R and Schwartz M (2015): Synthetic cannabinoid-related illnesses and deaths. The New England journal of medicine, 373(2): 103-107.

Vardakou I, Pistos C and Spiliopoulou C (2010): Spice drugs as a new trend: mode of action, identification and legislation. Toxicology Letters, 197(3): 157-162.

Von Der Haar J, Talebi S, Ghobadi F, et al., (2016): Synthetic cannabinoids and their effects on the cardiovascular system. The Journal of Emergency Medicine, 50(2): 258-262.

Waugh J, Najafi J, Hawkins L, et al., (2016): Epidemiology and clinical features of toxicity following recreational use of synthetic cannabinoid receptor agonists: a report from the United Kingdom National Poisons Information Service. Clinical toxicology, 54(6): 512-518.

Wilkins M, Williams K, Appel R, et al., (2013): Protien identification in Proteome projects. In: Proteome research: new frontiers in functional genomics, Springer Science, Switzerland, ch. (3), pp35-61.

Winstock A and Barratt M (2013): The 12 $\square$ month prevalence and nature of adverse experiences resulting in emergency medical presentations associated with the use of synthetic cannabinoid products. Human Psychopharmacology: Clinical and Experimental, 28(4): 390-393.

Yasar-Durmus S, Tuygun N, Akça H, et al., (2015): Bonzai intoxication in children: our experience with 17 cases. The Turkish journal of pediatrics, 57(5): 453.

Zanda M and Fattore L (2018): Old and new synthetic cannabinoids: lessons from animal models. Drug metabolism reviews, 50(1): 54-64. 


\title{
نمط التسمم الحاد بشبائه القُنَّب الإصطناعية لاى المرضى الذين تم استقبالهم بمركز علاج التسمم بمستثفيات جامعة عين شمس الاين ت برس
}

\author{
'أسماء عاطف هاشم وسوزان مصطفى محمود و رشا الحسيني أبو عنزة و ولاء جمعة عبد الحميد' \\ الملخص العربى
}

المقدمة: يتزايد التسمم الناتج عن استخدام شبائه القُّب الإصطناعية بشكل مطرد مع توافر بيانات محدودة تتعلق باستخدامه. تشمل الآثار الضارة الخطيرة بعد التعرض الحاد لشبائه القُنب الإصطناعية نقص تروية عضلة القلب والسكتة الدماغية والتشنجات والغيبوبة وإصابة الكلى الحادة.

الهدف من الدراسة: توصيف النمط الوبائي للتسمم الحاد بشبائه القُنب الاصطناعية لدى المرضى الذين تم استقبالهم بمركز علاج التسمم بمستشفيات جامعة عين

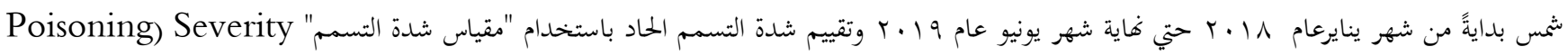

طريقة البحث: دراسة مستعرضة، أُجريت على جميع المرضى البالغين من كلا الجنسين الذين تم استقبالمم بمركز علاج التسمم بمستشفيات جامعة عين شمس بعد

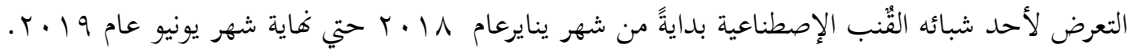

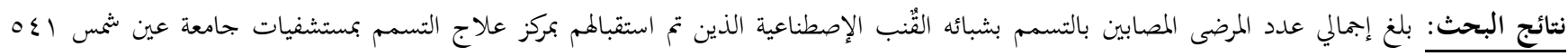

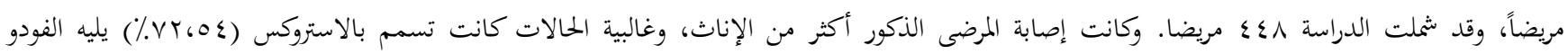

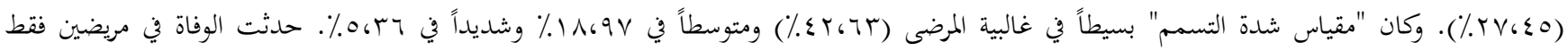

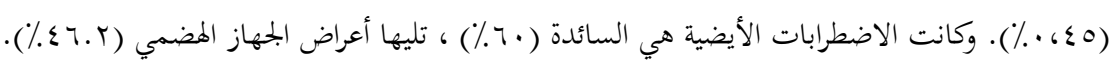
الخحلاصة: يتزايد معدل التسمم بشبائه القُنب الصطناعية في الأونة الأخيرة ويككن أن تؤدي العديد من المتغيرات إلى ارتفاع "مقياس شدة التسمم" مثل تقدم العمر

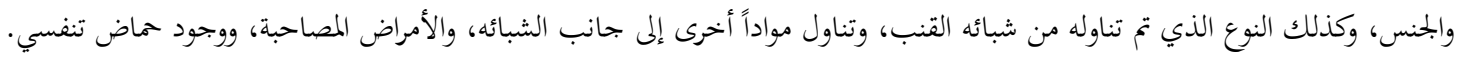
التوصيات: يمكن أن يساعد الجمع المبكر بين "مقياس شدة التسمم" وتحليل غازات الدم الشرياني في تحديد المرضى المعرضين لخطر الإصابة بالتسمم الحاد بشبائه

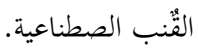

